\title{
Streak camera observation of the crystallization on multinary compounds
}

\author{
Naoki Shimidzu ${ }^{*}{ }^{1,2}$, Toshikazu Nagatsuka ${ }^{2}$, Norihiko Ishii ${ }^{1}$, Nobuhiro Kinoshita ${ }^{1}$, \\ and Katsuaki Sato ${ }^{2}$ \\ ${ }^{1}$ Science and Technical Research Laboratories NHK, 1-10-11, Setagaya-ku, Kinuta, Tokyo, 157-8510, \\ Japan \\ 2 Tokyo University of Agriculture and Technology, 2-24-16, Nakamachi, koganei, Tokyo 184-8588, \\ Japan
}

Received 24 February 2006, revised 10 April 2006, accepted 9 June 2006 Published online 4 September 2006

PACS 42.82.Bq, 68.08.De

A dynamic observation system for high speed crystallization has been developed using blue LD, high speed LD driver, streak camera and precise timing controller. We succeeded in dynamic observation of the crystal growth process of phase change materials induced by laser irradiation. The time-sequential development of crystallized region differs clearly between a eutectic composition $\mathrm{Sb}_{78} \mathrm{Te}_{22}$ and a pseudo alloy $\mathrm{Ge}_{2} \mathrm{Sb}_{2} \mathrm{Te}_{5}$, and the growth rate of $\mathrm{Sb}_{78} \mathrm{Te}_{22}$ crystal was determined to be at $0.28 \mathrm{~m} / \mathrm{s}$.

1 Introduction Phase-change recording materials (e.g. GeSbTe) are gaining attention as rewritable high-speed optical disks [1] and phase-change RAM (PC RAM) recording materials. These materials change phase in less than a few tens of nanoseconds. The phenomenology in phase-change materials is simple and is based on differences in reflection or electric resistance of crystalline and amorphous phases. The crystal growth in phase change materials has been discussed in terms of reflectivity change in accordance with the phase transition from an amorphous to a crystalline state, thermal analysis, X-ray structural analysis, and the like $[2,3]$. The exact crystal growth process during the crystallizationamorphyzation process is still obscure. Recently Alexander V. Kolobov et al of AIST have reported from detailed XAFS and XANES analysis that the phase-change process is not a real phase transition from amorphous to crystalline material, but rather a change in the crystalline phase [4]. Nevertheless, there is still much that is unknown about dynamic crystal growth mechanisms.

To observe high-speed transformation from the amorphous to the crystalline state of the phase change materials, we have developed a new prototype dynamic observation system. The crystal growth processes in $\mathrm{Sb}_{78} \mathrm{Te}_{22}$ and $\mathrm{Ge}_{2} \mathrm{Sb}_{2} \mathrm{Te}_{5}$ films induced by laser irradiation were observed.

\section{Experiment}

2.1 Sample preparation The phase-change film samples used for the present study were a $\mathrm{Sb}_{78} \mathrm{Te}_{22}$ film and a $\mathrm{Ge}_{2} \mathrm{Sb}_{2} \mathrm{Te}_{5}$ film, fabricated on a glass substrate by rf magnetron sputtering from the corresponding targets in an Ar gas atmosphere with $1.3 \mathrm{~W} / \mathrm{cm}^{2}$ rf power intensity. Most measurements were performed on as-sputtered films. For comparison, previously annealed samples were also examined.

For the dynamic observation of the $\mathrm{Ge}_{2} \mathrm{Sb}_{2} \mathrm{Te}_{5}$ film, a film stack with dielectric $\mathrm{ZnS}$ layers was used in order to improve the contrast between crystalline and amorphous states.

\footnotetext{
" Corresponding author: e-mail: shimizu.n-hg@nhk.or.jp, Phone: +81 35494 3201, Fax: +81 354943261
} 
2.2 Measurements The refractive index (n) and extinction coefficient of (k) of the $\mathrm{Ge}_{2} \mathrm{Sb}_{2} \mathrm{Te}_{5}$ film and $\mathrm{ZnS}$ film were calculated using an ellipsometry measurement, and the optimum film thickness was calculated using the OPTAS FILM analysis software.

Experimental setup of the dynamic observation system is shown in Figure 1. The light source part consists of a laser diode (wavelength: $405 \mathrm{~nm}$ ) and an objective lens. The system also includes a Xe flash lamp to provide illumination for observation, a streak camera capable of rapid time sweeping of an image (Hamamatsu Photonics C7700), and a CCD camera. Laser light, which is interrupted during observation, is completely blocked from entering the streak camera by a sharp-cut filter.

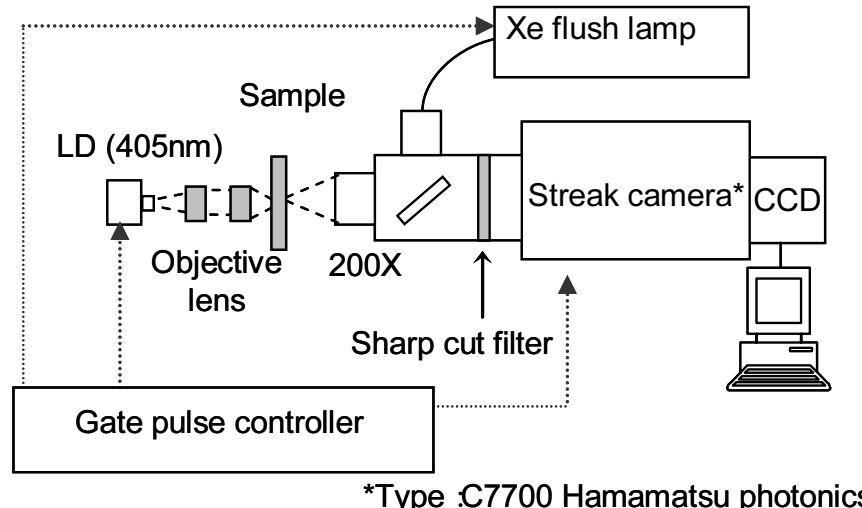

Fig.1 Experimental setup of the dynamic observation system

In order to observe the fast phase-change process, the operational timing of the LD light source, flash lamp, streak camera, and the like were accurately controlled by a gate-pulse controller. The timing of the sweep time was synchronized with the Xe flash lamp illumination, and the starting point of crystallization was observed by changing the timing with LD irradiation time. The laser spot size on the sample film was 1.5 micrometer in diameter and the laser power was $4 \mathrm{~mW}$. The observation was made as the temporal change of the spatial image on the sample film, with a laser irradiation time of 10 microseconds and a streak-camera sweep time of 1 microsecond.

\section{Results and discussion}

3.1 Thermal analysis of the samples Figure 2 shows the evaluation of the $\mathrm{Sb}_{78} \mathrm{Te}_{22}$ and $\mathrm{Ge}_{2} \mathrm{Sb}_{2} \mathrm{Te}_{5}$ films by DSC. In the $\mathrm{Sb}_{78} \mathrm{Te}_{22}$ film, an exothermic reaction was seen at $153^{\circ} \mathrm{C}$, and an endothermic reaction at $547^{\circ} \mathrm{C}$. Additionally, no exothermic reaction was seen in a sample that was heat-treated at $170^{\circ} \mathrm{C}$. From this, it is thought that the crystallization temperature is $153^{\circ} \mathrm{C}$, and the melting point is $547^{\circ} \mathrm{C}$.

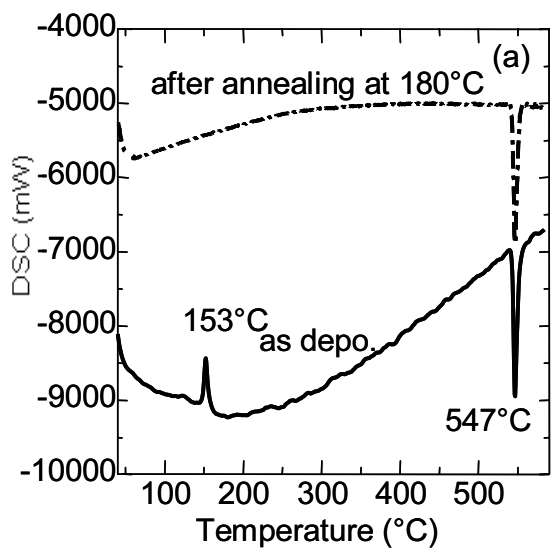

www.pss-c.com

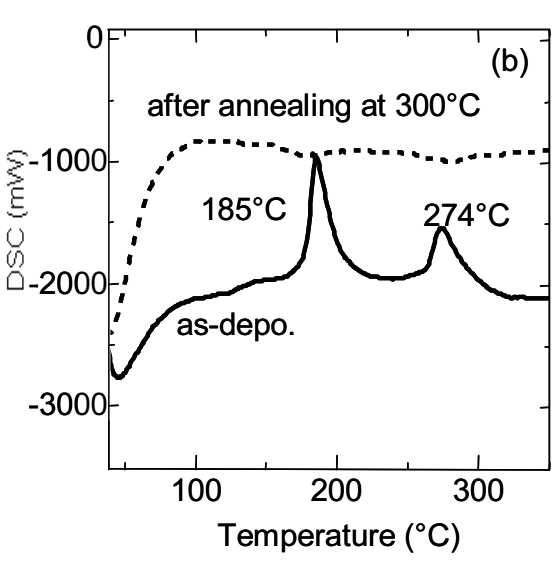

Fig.2

DSC measurements of

(a) $\mathrm{Sb}_{78} \mathrm{Te}_{22}$

(b) $\mathrm{Ge}_{2} \mathrm{Sb}_{2} \mathrm{Te}_{5}$. 
Meanwhile, it is that the $\mathrm{Ge}_{2} \mathrm{Sb}_{2} \mathrm{Te}_{5}$ film has a crystallization temperature of $185^{\circ} \mathrm{C}$, and at a peak of $274^{\circ} \mathrm{C}$, heat generation due to a shift in phase from a metastable crystal phase to a stable crystalline phase. Based on the results of DSC measurements, we used the $\mathrm{Ge}_{2} \mathrm{Sb}_{2} \mathrm{Te}_{5}$ film of metastable crystalline phase that was heat-treated at $230^{\circ} \mathrm{C}$ for ellipsometry measurements.

3.2 XRD and optical analysis Figure 3 shows XRD spectra of the $\mathrm{Sb}_{78} \mathrm{Te}_{22}$ film. From a comparison with the crystalline state due to annealing at $180^{\circ} \mathrm{C}$, it can be seen that the material is in an amorphous state immediately after deposition.

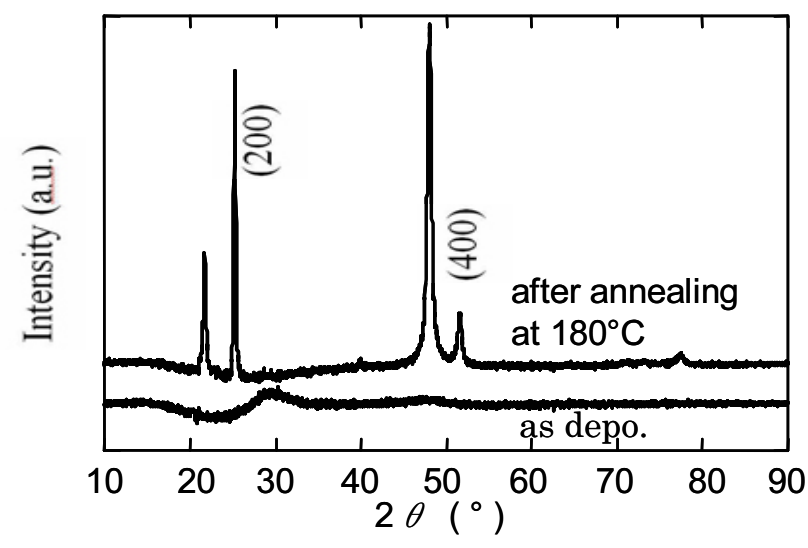

Fig.3 XRD spectra of $\mathrm{Sb}_{78} \mathrm{Te}_{22}$ films after annealing and as-deposited.

Table 1 shows the optical constants calculated from ellipsometry measurements. The sample used for the measurement was a $200 \mathrm{~nm}$-thick film fabricated on a glass substrate. From these refraction index $\mathrm{n}$ and extinction coefficient $\mathrm{k}$, the film calculation program of the OPTAS FILM analysis software was used to calculate the reflectivity of the $\mathrm{Sb}_{78} \mathrm{Te}_{22}$ and $\mathrm{Ge}_{2} \mathrm{Sb}_{2} \mathrm{Te}_{5}$ film in an amorphous and crystalline state under reflective light from the Xe flash lamp, and the thickness at which the optimum contrast ratio would be reached was calculated.

Table $1 \mathrm{n}$ and $\mathrm{k}$ of $\mathrm{Sb}_{78} \mathrm{Te}_{22}$ and $\mathrm{Ge}_{2} \mathrm{Sb}_{2} \mathrm{Te}_{5}$.

\begin{tabular}{lll}
\hline & $\mathrm{Sb}_{78} \mathrm{Te}_{22}$ & $\mathrm{Ge}_{2} \mathrm{Sb}_{2} \mathrm{Te}_{5}$ \\
\hline $\mathrm{n}_{\mathrm{a}}$ & 3.49 & 3.38 \\
\hline $\mathrm{n}_{\mathrm{c}}$ & 1.92 & 3.04 \\
\hline $\mathrm{k}_{\mathrm{a}}$ & 2.88 & 1.70 \\
\hline $\mathrm{k}_{\mathrm{c}}$ & 4.12 & 2.90 \\
\hline
\end{tabular}

Subscript ${ }_{\mathrm{a}}$ : amorphous state, Subscript ${ }_{\mathrm{c}}$ : crystalline state at $530 \mathrm{~nm}$

Table 2 Layer thickness of sample film.

\begin{tabular}{ll}
\hline & Thickness (nm) \\
\hline $\mathrm{ZnS}$ (upper) & 30 \\
\hline $\mathrm{Sb}_{78} \mathrm{Te}_{22}$ or & 40 \\
$\mathrm{Ge}_{2} \mathrm{Sb}_{2} \mathrm{Te}_{5}$ & 60 \\
\hline $\mathrm{ZnS}($ lower) & \\
\hline
\end{tabular}

In the calculation of the reflectivity in crystalline and amorphous states, we assumed that the incident light was coming from the $\mathrm{ZnS}$ side. The results are shown in Table 2.

3.3 Dynamic observation The results of dynamic observation of the crystallization processes of $\mathrm{Sb}_{78} \mathrm{Te}_{22}$ and $\mathrm{Ge}_{2} \mathrm{Sb}_{2} \mathrm{Te}_{5}$ film are shown in Figure 4. The vertical axis shows the elapsed time since a start 
of the laser irradiation, and the horizontal axis shows the position. The bright area near the canter of the image is the crystallized portion.

This is the first successful dynamic observation of crystal growth consequent to laser irradiation. In the $\mathrm{Sb}_{78} \mathrm{Te}_{22}$ sample, crystallization began 1.2 microseconds after the start of laser irradiation, while in the $\mathrm{Ge}_{2} \mathrm{Sb}_{2} \mathrm{Te}_{5}$ sample, crystallization began 5.3 microseconds after the start of laser irradiation. For the $\mathrm{Sb}_{78} \mathrm{Te}_{22}$ sample, we noted a lateral expansion of the crystallized portion. Upon termination of growth of the crystallized portion, the 2.7 micron-diameter wider than the beam diameter was obtained. The speed of crystal growth was calculated as $0.28 \mathrm{~m} / \mathrm{s}$ as . Meanwhile, no great change was seen in the size of the crystallized portion in the $\mathrm{Ge}_{2} \mathrm{Sb}_{2} \mathrm{Te}_{5}$ sample, and only the contrast to the amorphous area increased as seen in the cross-sectional profile of (a).

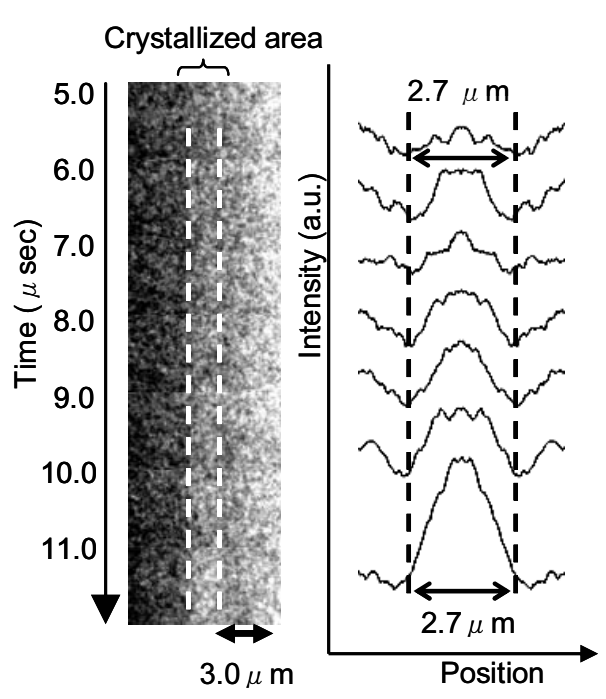

(a)

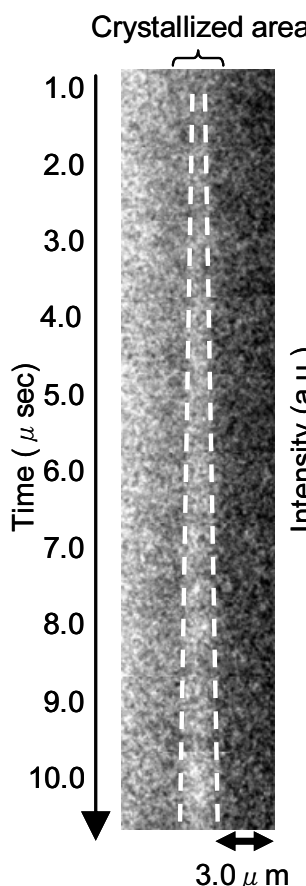

$3.0 \mu \mathrm{m}$

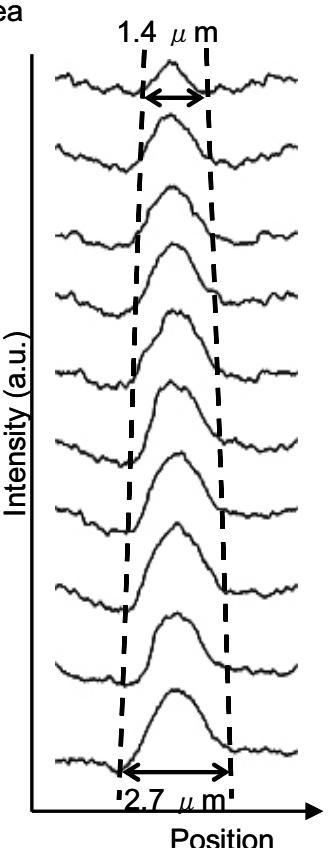

(b)
Fig.4

The dynamic observation results of

(a) $\mathrm{Ge}_{2} \mathrm{Sb}_{2} \mathrm{Te}_{5}$

(b). $\mathrm{Sb}_{78} \mathrm{Te}_{22}$

4 Conclusions The present research developed a novel prototype dynamic observation system using a streak camera, and for the first time successfully observed crystal growth in a phase-change recording material. The $\mathrm{Sb}_{78} \mathrm{Te}_{22}$ and $\mathrm{Ge}_{2} \mathrm{Sb}_{2} \mathrm{Te}_{5}$ films are used as typical examples for a eutectic alloy and a pseudo-alloy, respectively, for which different streak images were observed.

It is our future task to conduct a comparative study using the simulation of thermal analysis.

Acknowledgements This research was conducted as part of the $21^{\text {st }}$ Century COE Program of "Future Nano Materials" in Tokyo University of Agriculture and Technology.

\section{References}

[1] N. Ishii, N. Kinoshita, M. Kishida, N. Shimidzu, H. Tokumaru, Y. Fujita, and J. Numazawa, Technical Digest of EPCOS 2003 (2003)

[2] N. Yamada, E. Ohno, K. Nishiuchi, and N. Akahira, J. Appl. Phys. 69, 2849 (1991).

[3] N. Yamada and T. Matsunaga, Technical Digest of ISOM/ODS 2005 (2005)

[4] A. V. Kolobov, P. Fons, A. I. Frenkel, A. Ankudinov, J. Tominaga, and T. Uruga, Nature Mater. 3, 703 (2004). 